\title{
Fournier's gangrene following an ant bite in a healthy man: A very rare case report
}

\author{
Abbas Edalatkhah', Mohammad Ali Jafari' ${ }^{2}$, Sima Valizadeh ${ }^{1}$, Alireza Esmaeili ${ }^{2}$ Ehsan Zarepur ${ }^{3 *}$ \\ 'Trauma Research Center, Shahid Sadoughi University of Medical Sciences, Yazd, Iran \\ ${ }^{2} S c h o o l$ of Medicine, Shahid Sadoughi University of Medical Sciences, Yazd, Iran \\ ${ }^{3}$ Isfahan Cardiovascular Research Center, Cardiovascular Research Institute, Isfahan University of Medical Sciences, Isfahan, Iran
}

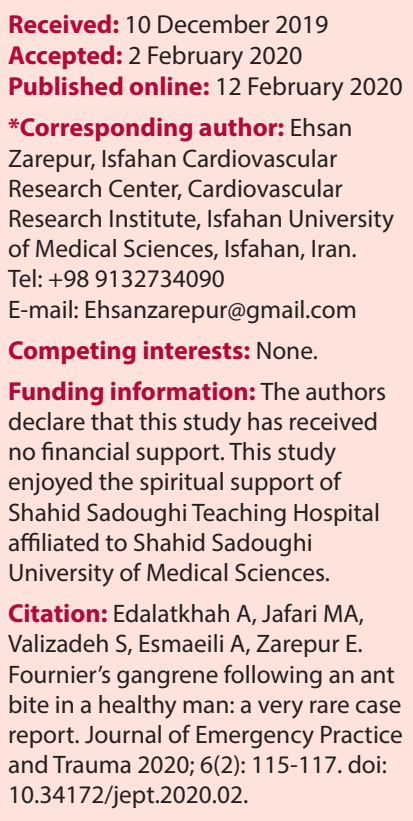

\begin{abstract}
Objective: Necrotizing fasciitis of the perinea, referred to as Fournier's gangrene, is a necrotizing infection of the perinea. To the best of our knowledge, there is no report on the Fournier's gangrene following an ant bite and this is a rare case report of this type. Case Presentation: In this rare case report we describe a 20-year-old man who developed Fournier's gangrene following an ant bite which resulted in his death. He sustained numerous ant bites in the perinea. Subsequently, he suffered from itching of the area and had scratched the area frequently leading to dermal ulcers and laceration, pain, and swelling of the scrotal area followed by fever and diminished consciousness. Finally, he presented to the emergency room (ER) after 72 hours of ant bites with a shock. Physical examination revealed extensive necrosis of scrotum. The primary treatments including antibiotic therapy, normal saline solution, and dopamine were not effective.

Conclusion: Even a simple nonpoisonous insect bite can lead to Fournier's gangrene and death. Paying greater attention to the site of bite, especially in the perinea which is anatomically more susceptible to infection, observing hygienic principles, and quick access to healthcare centers may prevent the patient's death.

Keywords: Fournier's gangrene, Necrotizing fasciitis, Fasciitis, Necrotizing, Case report
\end{abstract}

\section{Introduction}

Necrotizing infections of the soft tissue are rapidly progressing infections of the deep soft tissues and the fasciae around it. Necrotizing fasciitis of the perinea is called Fournier's gangrene $(1,2)$. Its incidence varies from 1:7500 to 1:750 000 and it is demonstrated with fever, local symptoms of the perineal area include inflammation and swelling, crepitation, erythema, superficial stiffness of the skin which progresses towards the anterior wall of the abdomen and is associated with ecchymosis and necrosis via drainage and gangrene of the perineal region and even septic shock (1-6). In the treatment of this disease like many other diseases, we must be careful. Its treatment management includes early diagnosis, rescucitation, rapid fluid compensation, debridement, and extensive parenteral antibiotic therapy (3-5).

The most common cause of Fournier's gangrene is local trauma or the spread of urinary or genital infection. Ulceration and dermal damage in the perineal region and inadequate hygiene may predispose an individual to Fournier's gangrene (6). Sing et al. reported 75 cases of necrotizing infection of soft tissue during a 5-year prospective study in which insect bite was the etiologic predisposing cause in 3 cases (7). One case pertained to a 31-year-old woman who underwent treatment for idiopathic necrotizing infection of the neck while her husband was afflicted with necrotizing infection of soft tissue of internal fasciae of the foot following an insect bite (8).

To the best of our knowledge, no previous case report has clearly introduced ants as the etiologic cause of necrotizing fasciitis. Therefore, this case report introduces a 20 -yearold man who developed Fournier's gangrene following ant bites resulting in his death.

\section{Case Presentation}

The patient was a 20-year-old man who presented to the emergency room (ER) with fever, hypotension, 
tachycardia, and reduced level of consciousness. In the primary investigation, he was in shock. According to the statements made by the patient's companions, he sustained numerous ant bites in the perineal and scrotal regions in a mountain-climbing camp 72 hours before hospitalization. The patient and two other climbers sustained bites by similar ants in the organs where the sites of bites improved with mild dermal reactions. After ant bites, the patient suffered itching of the bitten area and scratched the site frequently. Then, he developed pain and swelling of the scrotal region and experienced slight nausea 36 hours after ant bites. About 60 hours after the initial bites, the patient developed fever and diminished level of consciousness. Finally, he was hospitalized in the ER $72 \mathrm{~h}$ after ant bites in a state of septic shock. He had no other history of diabetes mellitus, immunodeficiency, or any other known diseases. Also, he had no allergy to various agents or insect bites and consumed no medicines (Figure 1).

The vital signs at admission and laboratory test results were as follows:

Blood pressure (BP): 80/P, Pulse rate (PR): 130, respiratory rate (RR): 23, T: 40.1, blood glucose (BS): 110, Glasgow coma scale (GCS: 10/15)

pH: 7.04, HCO3: 9.5, $\mathrm{PCO}_{2}: 25$

Blood culture: Polymicrobial

The primary interventions including Ampicillin/ sulbactam $3 \mathrm{~g}$ along with Metronidazole $500 \mathrm{mg}$, Normal Saline $2 \mathrm{~L}$ in the free form, and dopamine $10 \mu \mathrm{g}$ were not effective. Foley catheter was fixed. Despite initial treatments, the patient sustained cardio-pulmonary arrest 1 hour after admission at the ER and died after 1 hour of cardiopulmonary resuscitation (CPR).

\section{Discussion}

Inadequate hygiene is associated with a high percentage of Fournier's gangrene. The common dermal organisms below the lumbar region include a wide spectrum of gram positive and gram-negative microorganisms $(4,6,9)$. Late diagnosis, older age, anaerobic organisms, organs dysfunction, diabetes, and immunodeficiency deteriorate the prognosis of so many diseases as well as Fournier's gangrene. Moreover, if intravenous antibiotic is injected during the first hour of gangrene, it will decrease mortality $(9,10)$. The first step to be taken for any patient with septic shock is establishing an airway and breathing. The next step is making sure of blood supply to peripheral tissues and initiation of antibiotic therapy. Hypotension (systolic pressure less than $90 \mathrm{~mm} \mathrm{Hg}$, average pressure below 70 $\mathrm{mm} \mathrm{Hg}$, or a $40 \mathrm{~mm} \mathrm{Hg}$ drop in systolic pressure) is the most common index of inadequate perfusion $(6,9)$.

Rapid infusion of 3-5 L of IV fluids is the first line of treatment for septic shock. Norepinephrine is a selective vasopressor and is administered in the cases of tachycardia or phenylephrine arrhythmia (9).

The therapeutic goals in septic shock resuscitation include average arterial pressure $>65 \mathrm{~mm} \mathrm{Hg}$ (two times

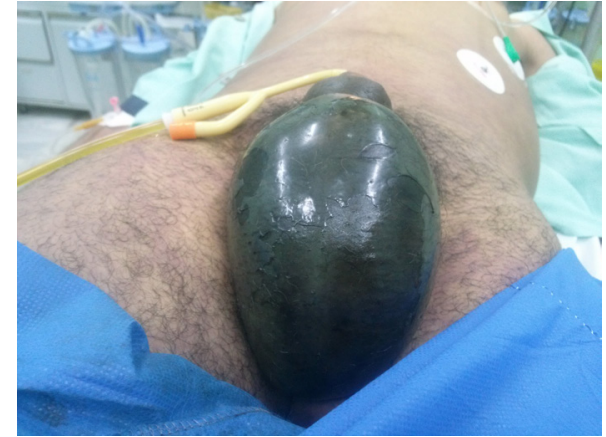

Figure 1. Necrosis and severe scrotal edema of the patient following ant bites and the subsequent itching.

the diastolic pressure plus systolic pressure divided by 3), minimal urinary output of $0.5 \mathrm{cc}$ per hour for every $\mathrm{kg}$ of body weight, CVP of 8-12 $\mathrm{mm} \mathrm{Hg}$, and superior vena cava oxygen saturation percentage $>\% 70(2,9)$. Resuscitation is effective in decreasing mortality only if it is started during the first 24 hours after initiation of sepsis. Nonetheless, initiating treatment after 24 hours of the onset of sepsis has no effect on mortality (9).

In our patient, rapid fluid therapy and dopamine administration were not effective in preventing death due to the delay in presenting to the ER as well as the critically ill state of the victim. A study by Unuigbe et al reported the case of a young healthy woman who developed gangrene in three toes following an insect bite; yet, gangrene occurred 2 weeks after bites. Besides, this woman had used traditional medicine, tapping the site of insect bites, and tight bandages due to foot swelling and inflammation. The possible cause of gangrene may be attributed to the role of bandage tourniquet (11). Verma reported a case of necrotizing fasciitis in a 73-year-old lady following a gnat (mosquito) bite which manifested as primary signs of erythema and edema. After itching, scratching, and ulceration of the skin, she performed traditional treatment with henna (Egyptian privet). Then, seeing no healing effect, she underwent treatment with oral cephalexin and tapping the site of infection. Again, there was no recovery and she progressed towards necrosis during 2 weeks (12). Moreover, in the report by Poitelea and Wearne, a 68-yearold man developed facial cellulitis and blepharo-necrosis despite extensive antibiotic therapy. Finally, he underwent extensive surgical debridement and skin graft (13) while none of the conditions were induced by an ant bite and were not in the perineal region.

Wide-spectrum antibiotic-based experimental treatment is devoted to gram-positive and gramnegative microorganisms. The patients should be treated by vancomycin along with one of third generation cephalosporins, beta-lactamase, or carbapenem until the status of their microbial infection is determined. Pseudomonas is probably covered (9). Corticosteroid therapy can be helpful in septic shock (systolic pressure $<90$ $\mathrm{mm} \mathrm{Hg}$ ) which does not respond to sufficient resuscitation 
with fluids and administration of vasopressors (9). Prevention of death is dependent on early diagnosis and invasive surgical intervention while delayed intervention can lead to increased mortality (14).

In this patient who manifested skin mottling, perineal and hypogastric crepitation and metabolic acidosis at admission in the ER, primary antibiotic therapy including Ampicillin/sulbactam $3 \mathrm{~g}$ along with metronidazole 500 $\mathrm{mg}$, and primary treatments of resuscitation were not effective and the patient died. Apparently, inadequate hygiene, late admission at the ER, rapid progressive course of gangrene, late diagnosis, and demonstration of shock were predisposing factors in the patient's death.

\section{Conclusion}

Even a simple bite by nonpoisonous insects may lead to skin maceration and necrotizing fasciitis. Hence, physicians must immediately start therapeutic interventions such as fluid and antibiotic therapy for these patients. Perhaps the patient's life could be saved if better hygiene was observed and the patient had quick access to a healthcare center.

\section{Acknowledgements}

The authors thank the patient's family and his companions and also the personnel at the ER of Shahid Sadoughi Hospital. Informed consent was obtained from the patient's father for the case to be reported.

\section{Authors' contributions}

All the authors meet the standard criteria of authorship based on the recommendations of the international committee of medical journal editors.

\section{Ethical issues}

Informed consent was obtained from the patient for publication of this report.

\section{References}

1. Aghaeeafshar M, Shahesmaeili A. Necrotizing fascitis in a 47-year old diabetic man: case Report. Journal of Kerman University of Medical Sciences 2009; 16(4): 405-9. [In Persian].

2. Mahdizadeh F, Safari S. Concurrent hand and penile gangrene following prolonged warfarin use; a case report. Emerg (Tehran) 2017; 5(1): e71.
3. Jafari M, Biuki AA, Hajimaghsoudi M, Bagherabadi M, Zarepur E. Intravenous haloperidol versus midazolam in management of conversion disorder; a randomized clinical trial. Emerg (Tehran) 2018; 6(1): e43.

4. Sasannejad P, Rezaei F, Bidaki R, Zarepur E. Rare presentation of moyamoya disease with sub acute presentation in Iran. Iran J Child Neurol 2018; 12(1): 8993.

5. Yeniyol CO, Suelozgen T, Arslan M, Ayder AR. Fournier's gangrene: experience with 25 patients and use of Fournier's gangrene severity index score. Urology 2004; 64(2): 218-22. doi: 10.1016/j.urology.2004.03.049.

6. Korkut $M$, Içöz G, Dayangaç $M$, Akgün E, Yeniay L, Erdoğan $\mathrm{O}$, et al. Outcome analysis in patients with Fournier's gangrene: report of 45 cases. Dis Colon Rectum 2003; 46(5): 649-52. doi: 10.1007/s10350-004-6626-x.

7. Singh G, Sinha SK, Adhikary S, Babu KS, Ray P, Khanna SK. Necrotising infections of soft tissues--a clinical profile. Eur J Surg 2002; 168(6): 366-71. doi: 10.1080/11024150260284897.

8. Aimoni C, Cilione AR, Grandi E, Lombardi L, Merlo R, Pastore A. Cervical necrotizing fasciitis. Eur Arch Otorhinolaryngol 1999; 256(10): 510-3. doi: 10.1007/ s004050050201.

9. Schmidt GA, Mandel J. Evaluation and management of severe sepsis and septic shock in adults. UpToDate; 2013. Available from: https://www.uptodate.com/contents/ evaluation-and-management-of-suspected-sepsis-andseptic-shock-in-adults.

10. Imanian M, Ghasemzadeh MJ, Zarepur E, Zarepur A, Sarbandi Farahani R, Sarbandi Farahani R. The Relationship between Pneumonia with parental smoking in children under 10 years old: a case- control study. Int J Pediatr 2018; 6(6): 7791-6. doi: 10.22038/ijp.2016.7801.

11. Unuigbe EI, Ikhidero J, Ogbemudia AO, Bafor A, Isah AO. Multiple digital gangrene arising from traditional therapy: a case report. West Afr J Med 2009; 28(6): 397-9.

12. Verma SB. Necrotizing fascitis induced by mosquito bite. J Eur Acad Dermatol Venereol 2003; 17(5): 591-3. doi: 10.1046/j.1468-3083.2003.00819.x.

13. Poitelea C, Wearne MJ. Periocular necrotising fasciitis--a case report. Orbit 2005; 24(3): 215-7. doi: 10.1080/01676830590930634.

14. Jones AE, Brown MD, Trzeciak S, Shapiro NI, Garrett JS, Heffner AC, et al. The effect of a quantitative resuscitation strategy on mortality in patients with sepsis: a metaanalysis. Crit Care Med 2008; 36(10): 2734-9. doi: 10.1097/ CCM.0b013e318186f839. 